\title{
The educational impact of the Covid-19 rapid response on teachers, students, and families: Insights from British Columbia, Canada
}

\author{
Margaret MacDonald ${ }^{1} \cdot$ Cher Hill $^{1}$
}

Accepted: 2 December 2020 / Published online: 15 January 2021

(C) UNESCO IBE 2021

\begin{abstract}
The government's rapid response to the spread of Covid-19 in British Columbia has resulted in drastic and unprecedented changes to the delivery of K-12 education. Using qualitative research methods, including remote in-depth interviews, this article addresses the question: What is the educational impact of the Covid-19 rapid response on teachers, students, and families in the Lower Mainland of British Columbia, Canada? Six themes are discussed, including teacher and family responses to change, vulnerability, transitions, work/home life balance, holistic teaching practices and communication. The article ends with recommendations relating to the communication and implementation of health, care, and educational practices that better attend to vulnerable populations and address social emotional wellness.
\end{abstract}

Keywords Covid-19 $\cdot$ K-12 education $\cdot$ online teaching $\cdot$ remote learning $\cdot$ Canada

On March 17, the British Columbia (BC) government suspended K-12 classroom instruction as a result of the Covid-19 pandemic, providing home schooling opportunities to ensure the "continuity of learning" (Ministry of Education 2020). Later, that same government announced that schools would be reopening June 1, 2020. Class size and hours of operation were modified, based on "scientific information", as a trial run for September (Horgan 2020). Attendance was not made mandatory and families could continue with online learning if they choose. Although some others had fewer Covid-19 cases, BC was the only Canadian province to open high schools at that time, and (other than Quebec) the only province to reopen elementary schools (Government of Canada 2020). In the wake of this announcement, public forums erupted with parents questioning whether it was safe

Margaret MacDonald

margaret_macdonald@sfu.ca

Cher Hill

cher_hill@sfu.ca

1 Faculty of Education, Simon Fraser University, Burnaby, BC V5A 1S6, Canada 
to send students back at this time, expressing concern about the emotional wellbeing of children returning to classrooms where they could not hug friends or share toys, and wondering whether the "new normal" of school would be frightening for children who had been sheltered from the reality of the pandemic at home. Other parents expressed relief at having some respite from childcare duties, excitement that their children would be reunited with teachers and friends and have closure to the school year, and appreciation that those struggling to learn at home would have more support. Teachers questioned how they might keep children safe without frightening them and wondered how to support both online and face-to-face learning simultaneously. They also expressed concern for their own wellbeing, and that of their families.

While there is much research on the impact of short-term school closures with regards to the spread of the H1N1 virus (Earn et al. 2012; Lee et al. 2010; Wu et al. 2010) and to financial costs (Effler et al. 2010; Johnson et al. 2008; Sadique et al. 2008), little is known about the social, emotional, and pedagogical impact of extensive school closures for families and teachers, or about the consequences of a gradual return to school with many new safety protocols, along with hybrid options for learning.

\section{Methodology}

Following approval by the Simon Fraser University Research Ethics Board and after obtaining informed consent, we conducted in-depth audio interviews to capture parent and teacher experiences of the rapid response to Covid-19, including school closures, online instruction, and modified return to face-to-face instruction. Contextual information was also gathered from the participants. Each interview lasted approximately one hour. Parent and teacher experiences of "sheltering in place", remote instruction, and modified returns to school as part of the provincial pandemic response were discussed, as were the experiences of their students and children during these same time periods. Each interview was transcribed and then thematically analyzed (Saldaña 2016), first individually and later by comparing responses across parent and teacher interviews. We identified six major themes: Change, Vulnerability, Transitions, Work/Homelife Balance, Holistic Teaching Responses, and Communication.

\section{Participants}

We conducted on-line audio interviews with six parents, who had school-aged children ranging from elementary through high school, and with nine teachers. Two of the teachers also had children attending school in the same district. Of the eight parents, six were part of two-parent families and two were single parents. In all but two families, the parent(s) normally worked full-time outside the home. In terms of occupations, the parents working outside the home included post-secondary educators (teaching online at the time of the interviews), an animal rescue worker, a supervisor for a group home, as well as the two teachers. All the parents interviewed were women, as were seven of the teachers. Two families had immigrated to Canada, one coming from China and the other from England. Most families resided in areas that would be considered middle class. All the families had two or more school-aged children, and three families had at least one child with a designated learning disability, including ADHD and autism. The nine teachers who were interviewed 
were from the same district and taught in a variety of contexts, including elementary classrooms, a Montessori focus, Distributed Learning (K-9), middle school, and high school (French Immersion). Five of the teachers interviewed had 10 or more years of experience and were working full-time, while the other four were early in their career.

\section{Themes}

During the interviews, parents and teachers had the opportunity to discuss their experiences openly. Each of the sections below represents a major theme that was discussed, animated by a series of quotes from both groups. At times, we used clarifying questions to verify information. All the direct quotes used in this articles were emailed back to the participants to confirm their accuracy. We assigned pseudonyms to the participants and include some contextual information with the quotations to clarify each participant's circumstances. We felt these details were important to our interpretation of the discussion and findings. Quotes were selected that represent the essence of the main themes and bring to life some of the participants' thoughts and feelings. Notably, the teachers interviewed are experienced professionals and/or well-supported early career teachers, and most of the parents are also well-supported socially and economically. Therefore, we expect that the concerns and stressors they mention would be amplified among more marginalized or vulnerable communities of teachers or parents.

\section{Change}

\section{Changing rhythms}

These are rare and unprecedented times in the history of provincial, national, and even global education-both our school systems and our lives have been disrupted unexpectedly. Both parents and teachers noted the change from normal routines and practices to isolating in place, remote instruction, and physical distancing. Social interactions and extracurricular routines outside the home shifted suddenly to an intense focus on family and home life, often including working from home. Participants reflected on what they valued, how they lived, and how they engaged with others before and after the pandemic response. Notably, rhythms and routines changed for families as they attempted to establish safe daily practices, including extracurricular activities and recreation.

After the extended spring break, parents became more invested emotionally and materially in their children's learning. This included trying to schedule manageable daily educational routines from home as they navigated different assignments, submission processes, web platforms, and computer needs. For the families we interviewed, this learning included two or more children in different grades who had differing abilities to self-regulate and complete tasks independently. Parents of middle and high school students said they felt like their children were younger again given their increased involvement with them. Families purchased equipment and supplies to support their children's learning, and they created new workspaces within their homes. It soon became clear to families that everyone required their own device as online meetings often overlapped. Children's sleep patterns changed, they stayed up much later than usual, and weekdays and weekends blurred. 
This was difficult to regulate, particularly for parents who continued to work outside of the home. Work rhythms for teachers also shifted as all learning moved to the online environment.

For some, the pandemic provided a pause and a reset, creating a much-needed opportunity to recharge and focus on wellness. As one teacher whose children were older noted,

I was actually able to get a little more sleep. I didn't have the stress of driving every day and I think healthwise I was more healthy [than] in a long time just because I was able, ... to create my schedule and get a little more rest... I found that this was kind of a blessing in disguise at this time in my life-being able to take things at my own pace. (Mia, K-9 distributed learning teacher)

For some teachers, this was a time of tremendous professional growth, as they experimented with new technologies as well as new pedagogies, and attended free and easily accessible professional learning webinars. For others, the pandemic meant a chaotic upheaval of unrelenting work to support their communities, as well as their own children. This was particularly challenging for single mothers. One elementary school teacher who is a mother of two, a department head, and a technology leader in her school worked non-stop for the first two weeks after returning from spring break, so she could transition her teaching, reach out to her students, and support her staff. As she put it,

Spring Break was fine, but then we were told "we're teaching online", ... it was nonstop work for me. I was one of the technology teachers so I ... [was] constantly working all the time because I was trying to help and I did help a lot of the staff. I was one of the "go tos". There was three of us. So, I think that was exactly when it started going for the worse because we couldn't do our family things. We couldn't do what we were trying to do to make the best of the situation. There was no time. The girls were basically left alone to fight and just play on their ipads, have their screen time forever. And then exhaustion set in for those two weeks. It was very crazy. And then, it stayed like that for a few weeks. And then things started becoming better. And then another switch, now you are going back to work, to continue doing the remote, and now the in-class teaching. (Brenda, technology teacher and single parent of 2)

Brenda felt that she survived only because she is a veteran teacher. Some parents also described similar experiences of unmanageable expectations. One essential worker and single mother of three, who works an eight-hour shift and has a two-hour commute, began her second shift at home after a ten-hour day:

When I come home, I have to do homework. And I have to make dinner and I have to clean up a sink full of dishes they did from the daytime. I'm irritated...I guess they assume that everything was on lockdown, [that] everybody is staying home. And they're not taking into consideration that there's people that didn't have a choice. (Sara, single mother of 3)

\section{Change to asynchronous learning}

For teachers, the change to remote instruction, mandated by the district, meant a reduction in the number of synchronous hours of instruction, with an additional focus on task-oriented materials that could be assigned and completed asynchronously. Some parents worried that what was being provided was not enough. 
I was really baffled when I had heard that the district say "what you're striving for is an hour a day of work" and I'm like, "if they're doing an hour a day like what's happening in the other five hours at school?" So I was disappointed by that...I don't want my kids to fall behind. (Rochelle, parent of 2 children in elementary school)

Some families struggled to keep up with the assigned workload, and the lack of synchronous support was problematic. This created much stress, particularly for students with exceptionalities who lacked the kind of support that they normally received at school, and for parents who could not provide ongoing support and oversight throughout the workday. One family with two high school students, who were striving to send their children to university, had to adjust their expectations. As the students' mother noted, "We're trying very hard to make it so that our kids even just pass". She described how her daughter's teachers were only online for short periods of time to assign work, rather than to teach. She questioned, "how am I supposed to teach my kids when...I'm having a tough time understanding it, or I understand it but I'm doing it a different way than what the teacher expects?" (Sara, single mother of 3).

\section{Changing pedagogies}

Some teachers described how they worked very hard to maintain their usual pedagogical approach, creating engaging and meaningful projects for students to complete at home. They were surprised, however, when some parents requested that they send worksheets instead. One teacher tried to explain to parents that worksheets weren't typical in her classroom and encouraged parents to engage with the projects she assigned. But she found herself "falling back a bit on worksheets, because that's maybe what people are used to or feel like that's what school looks like" (Roslyn, kindergarten and grade 1 teacher). During the interviews, a mother of three children mentioned that some learning assignments were too involved and required too much parental support, which was unsustainable during her demanding workday. She printed off her own worksheets that her children could complete independently, with less one-to-one support, when it was not possible to help her children do the assigned work.

\section{Changing teaching environment}

Synchronous learning within online environments also posed challenges for students and teachers, as everyone was privy to all communications and non-verbal commutation cues were limited.

$K$ had a hard time asking questions because she didn't want to look like an idiot in front of everybody. Right? So they're not going to ask...or say "I don't understand", because they're going to feel like an idiot in front of everybody. Whereas in the in a classroom, the teacher walks around and they can ask and it's private, nobody else can hear. (Sara, single parent of 3, essential service worker)

I think it takes a lot more effort to connect in the digital domain. Not hearing all these conversations you're not watching the body language you're not actually able to be in there with him sometimes just sitting beside them to build some of that relationship and silence together but just being in the space too. (Jan, primary teacher and Montessori resource consultant) 
In general, this shift also meant teachers were more "directive" and prescribed more individual assignments. They also felt that they were holding relationships in a very tentative way, noting difficulty connecting with their students.

We come to circle which is not a circle it's just a bunch of boxes on the screen so we come just to connect every morning just checking about how things are going, to just free share that these are some things that are on my mind here are some concerns that I have. You know it's my chance to step back and just observe and listen again, so we started with that and then we've continued with the work plan for the week but it's been a lot more prescriptive...it's a band aid solution it feels uncomfortable to be that prescriptive but I think families needed that to know that a professional was guiding the learning in a way that parents could access. (Jan, primary teacher and Montessori resource consultant)

I mean I think on a pedagogical level my teaching as a practice really thrives on the connections I make with kids...so you don't get a chance to joke around there's not enough time to stop by and say how is your soccer game. (David, Grade 9-12 French Immersion teacher)

\section{Vulnerability}

The changes brought about by the pandemic response produced stress among all the adult participants, but the degree of stress and ability to respond to those challenges differed for each teacher or parent. Participants in both groups worried about children who experienced learning differences, isolation, and withdrawal. Reaching out to these children to support their learning was an utmost concern. With elementary and middle school students, parents reported distractibility, difficulty getting their child or children to adhere to routines, and an increased involvement with video games. With high school students, parents were concerned about their children's withdrawal from social networks and again found that their children were connecting to their peers via video games (e.g., Minecraft, Fortnite, Destiny 2, Overwatch, CSGO, Call of Duty, or Rainbow 6 Siege), as a way to maintain social involvement while being remote.

While online gaming alleviated some concerns about teenagers' lack of opportunities to socialize with peers, it also created conflict over enforcing educational routines and expectations. In a few cases, children resorted to sneaking games in during "homework" time or staying up late playing games. As a result, they were exhausted during their scheduled morning class meetings or simply slept through them, particularly when their parents were working outside of the home. The parents of all the children we spoke to utilized strategies like creating timetables and assignment charts, and they took an active role in organizing their children's deadlines and activities (both educational and extracurricular). In some cases, parents were worried about their children's mental health and isolation and the strain/confrontation that they were experiencing in their relationship with their child, as they navigated their new roles as their children's teachers. For some, the dual roles of parenting and teaching were overwhelming, even for parents who were professional teachers, which created a great deal of stress and conflict within the household.

The most challenges, would be just a strange relationship of being together so much. And so, I feel like it's been strained and harder. It's not good. I think it creates a lot more emotional stress on the kids for sure, with parents having to jug- 
gle this. You're not just their mom you're their teacher, so whereas you were just sometimes helping with homework, now it's much more. It's created a lot more chaos and this strained relationship between mothers and kids. (Brenda, technology teacher and single parent of 2)

Homeschooling was the biggest change for me and the kids just adapting to it and scheduling 4 different kids on one computer and 1 laptop organizing meetings the very first 2 weeks. I'll be honest I was out of my mind, stressed beyond belief wanting to make sure that everybody was doing everything properly. (Elise, parent of 4 children in elementary to high school)

I would have to sit with him through every class and every assignment just to make sure that he stayed on task and up to date and, if something would go wrong, he'd get very upset, so that added a stress level. (Elise, parent of 4 children in elementary to high school)

Generally we're fine. We just do math, language arts, but sometimes I would like to give my opinion or say maybe you change sentences and they you know "oh, mom, your grammar, your English is bad, you're never right, yeah, yeah, so stop telling me what I need to do". (Tia, parent of 3 children in post secondary, middle school, and elementary school)

In some cases, parents got overly involved in their children's schoolwork because it was the only available strategy to get the work completed, or because it reduced pressures and conflict in the household.

So, I found that really challenging because some kids I could tell that their work was not their own. It was parents helping them. Their writing, overnight went from filled with spelling mistakes to zero spelling mistakes or using verb tenses that we've never studied and that they probably can't conjugate if you just ask them on the spot, but there it is in their writing. (Karley, grade 7 and 8 French Immersion teacher)

Many children who faced challenges in their learning prior to Covid-19 were now particularly vulnerable, and it often required parents working collaboratively with teachers to get them back on track.

Well there were definitely kids that were struggling before Covid hit that kind of used this as an opportunity to completely check out. I definitely had a few kids that...it's just impossible to get a hold of them so they wouldn't show up the class they wouldn't email you back you try to initiate a phone call on teams if they decline it and it's really tough to follow up in that sense so even though we got the parents involved sometimes the parents would reply and sometimes not. It ended up being a really long process to get kids back on track if they got that contact at all. Those kids were, you know, decided to completely disengage or may be engaging inconsistently where they would pick and choose. I think [remote learning] created some trust issues because you know we had a lot of kids cheating because we weren't able to supervise we try to do assessments and they would swap answers it was really tough to keep tabs on that so I think it gave kids that decided early that they weren't very interested in class to just totally disconnect without having much follow up or maybe not having follow up in the same way that they normally would. (David, grade 9-12 French Immersion teacher) 
Although some children's attendance increased when learning moved online, as they now had nowhere to go, other children who were struggling with online learning had to resume face-to-face instruction in order to successfully complete their courses.

So we did have about four or five students that we would maybe call vulnerable learners. We identified those students, and...we brought them to the school. They had an amazing teacher that they were working with...one on one. And if we had not done that, they would not have passed. They were all grade nine students that already struggled with attendance, and most of them...wouldn't sometimes get on onto the [Microsoft] teams, they...wouldn't be there. So we had to bring them in... We weren't about to let those students that are struggling with a virtual connection... glide through. We really wanted to see them finish strong. (Mia, K-9 distributed learning teacher)

We also heard that online learning was problematic for parents of international students and that they were choosing to withdraw their children from school for the Fall. One parent shared that many of her daughter's friends would not be returning to school because their parents didn't feel that online remote learning for English was as valuable as having the social contact and emergent learning experiences that traditionally took place within school communities during face-to-face language learning.

Children with special needs or exceptionalities were particularly vulnerable when schooling moved online and support systems were interrupted. Although these children continued with some face-to-face learning, it was limited and limiting, and in some cases, insufficient.

One of [my returning students] was a special needs child whose family member was considered a frontline essential worker. Yes. She was there more often, but she ended up working on her own because she couldn't social distance very well...[We] went back to segregation. It wasn't an inclusive model for this. It was still helpful for the child to be in a routine and it gave parents a break, and during playtime outside that was as per usual. But it felt like a step backwards to have that person in a separate place, right. (Rosalyn, kindergarten and grade 1 teacher)

J. had to continue because of his learning disabilities. He struggles to catch up anyways. So if he didn't continue he would have been so far behind. In the early stages when it was getting too difficult...I contacted the school, his case manager and told her that you know, just some issues. We're really starting to see some changes. Can you help? So she actually got his EA to check in on him every day. And they've worked on some projects together as well. But even then, it was very difficult. (Jule, parent of two children with designations)

They're not taking into account [that] there are kids that need that access now. I mean my daughter has ADHD. Some other kids that have, I'm sure there's dyslexia and, other learning difficulties. They're not getting the help that they need. (Sara, single parent of 3, essential service worker)

For students who had been identified as needing additional support, Student Assistants (SA), Educational Assistants (EA), and Learning Assistant Teachers were found to be helpful.

I will say, though, that there is one, learning assistance teacher...who is absolutely amazing. Yeah, and worked really hard, [so that] D. could just pass. So she took extra time out of her day to do the [Microsoft] teams with D. She went into the school when they were allowed to go in and had it arranged so that D. [could] go in a cou- 
ple times a week to get that done. You know she was just really, really good, really good. She knew that I was working. She knew that and so she actually worked around D.'s schedule...if D. was sleeping till two or three in the afternoon, she would go in with her at two or three o'clock in the afternoon. There were days that she would [also] respond to her after school hours. (Ellyn, parent of 3 children, 1 with a designation)

However, both teachers and parents reported that this additional support was difficult to coordinate and less effective in cases where students needed ongoing one-on-one support for organization, communication, and social involvement. These limitations were difficult to overcome. One parent described how her son, who has autism, struggled with organization when much of his learning moved online. This created extreme frustration when he worked diligently on assignments but struggled to successfully submit them.

He needs that routine. He needs someone with him all the time to keep him organized. Even if he can do the work, he doesn't necessarily organize himself. So he loses his work, he does it all and forgets to hand it in, he presses delete. He doesn't realize that something is supposed to be handed in so he doesn't hand it in. So he is just not organized at all. At school he's got an EA to help him with that. She [the EA] can do the work with him [online] and things, but she can't see how he is organizing it on the laptop. She can't make him send it in even though he says he has sent it. She can't check that he has sent it. She can't sit there and monitor him while he is doing the work to make sure he is not going off on a tangent because sometimes he is hyper focused...missing what the actual question was. When she is at school, she stops him from doing that. (Jule, parent of two children with designations)

Students tended to fare better if they could work independently, or if their parents could devote time and effort to supporting them. This meant that home/school/work life was especially stressful for families with parents who were working (either commuting or working from home) and who had one or more children needing additional and ongoing support. In the most extreme cases this created unimaginable stress for parents and students, as well as conflict between siblings. When asked if she was concerned about her own wellbeing, one parent replied,

Yeah. My own wellbeing and just having peace. I talked about this all the time to [the girls] - you don't need to be asking me all these things. I just would like peace, like basically peace and quiet. My own well being, and doing what I want [but now] we just have so much [school] work to do. (Brenda, technology teacher and single parent of 2)

J hasn't spoken to [his brother] nicely since this situation started. [The brother] only has to breathe and J says "I can't stand this. Stop this noise. Get out of the room. I don't want to be near you". You know he can't tolerate any noise right now. We think it's because of the stress of the work. He's been a bit better in the last two days since I guess all this works handed in and there's nothing much he can do now about it. It was at the point where the last couple of weeks I've been crying practically every day. (Jule, parent of two children with designations)

Even for families with one or both parents supporting their children's learning and in families whose children had no designated challenges, this strain also showed up when parents felt incapable of supporting certain subject areas, particularly Mathematics, Reading, and English. Parents were frustrated and worried that their children would fall behind, 
especially non-teacher parents. Both parents and teachers noted, however, that for some students who were normally distracted at school-such as those who faced social anxiety or who had difficulty with peer relationships-learning remotely with the support of their parents was less stressful than learning in the busy school environment. These students showed an increased ability to engage with their learning and felt more successful.

I think kids are very resilient the only concern for me was the math for my older son I think that missing out on some certain concepts...there's not enough time and there's not enough one on one time to learn all of it, like trigonometry got cut down massively and so he's my concern all the math 10 students or 11 that are going on to the next grade they might struggle. (Elise, parent of 4 children in elementary to high school)

My second one is quite independent but isolates himself-he's a loner he doesn't want to be involved with many people, even before the pandemic when school was open. He only has a very few good friends, he feels comfortable just to stay home but I worry about the way he is now, when he was at school at least he had that connection, the connection with his classmates no matter how close or far. (Tia, parent of 3 children in post-secondary, middle school, and elementary school)

Although working so closely with their children was sometimes frustrating, this time together provided parents more insight into their children's learning. Parents were generally aware of their children's, dispositions, strengths, and stretches, but the extended support gave them more insight.

It made me realize that each of my children are different and they learn differently seeing $L$ kind of jumping around moving around during meetings and not paying strict attention gave me some insight into what my children must look like as students at school. (Elise, parent of 4 children in elementary to high school)

\section{Transitions}

The theme of uncertainty about what school might look like in September came up repeatedly across participants. There was also concern about the idea of the 'new normal.' This phrase, used commonly in the media, was repeated by participants who reflected aloud on what that normalcy might look like, both for themselves and for their children. They also expressed concern about possible waves of infection and response scenarios in the Fall. For parents and teachers of grade 12 students, there was also a concern about a lack of closure for the students, who were aware that they were not likely to see their peers, teachers, and school again. Some grade 12 students took advantage of the chance to return to school when it re-opened in June, but both parents and teachers commented that so much had changed for them that this experience was not the same as participating in a graduation ceremony or socializing with their peers and teachers.

I get emotional...he never knew that he was going to leave on March 13th and never return so he said to me "mom, I know you don't want me to go but I just want to see what it is one more day to be in grade 12". So we let him go and unfortunately he was [crying] I'm so sorry, he's my oldest, he went to his guitar class, he was the only student...he then had fitness and conditioning and active learning which takes place in the gym, he was told they weren't allowed to be in the gym or be on the equipment so he came home. He had his lunch break he went back for English. He 
was one of two students so after that I let the school know he wouldn't be returning for the remainder because obviously it wasn't the same thing and at home he could stay safer and it actually made him sad to go back because yeah, it wasn't the same. (Elise, parent of 4 children in elementary to high school)

Online I think the first discussion that we had was about "what are you worried about missing out on?" And...I think a lot of them understand that the social groups that they have now won't necessarily last after high school so that was sad to not be able to kinda live out those last days. I know there are a lot of kids who we're looking forward to grad obviously they had their dresses and their suits already...that's something that they've been thinking about for a long time. (David, grade 9-12 French Immersion teacher)

Teachers also expressed concern about induction years (Kindergarten, grade 6, and grade 9) where creating community among students joining elementary, middle, and high school in the Fall is expected to be much harder. Although some teachers were able to provide very creative "drive-thru" visitation experiences for students who would be new to their schools in September, face-to-face orientations were not possible, which heightened anxiety for some students. These entry years were seen as pivotal to establishing learning communities and sharing expectations. Especially in Kindergarten, there was concern around socialization and addressing the transition from home to school. One kindergarten teacher expressed that during the pandemic, she encouraged parents to do whatever was best for their family; however, she wondered what that might look like in the fall.

... it's a little bit worrisome to do that again in September when you're just kicking off. Yes, it's different than when you're winding down for the year... We'll figure out ways to reach out and be creative and so there's that worry in the back of my head but I've tried just to keep it at bay because, yeah, we can't deal with what we get handed we don't know what that is yet. (Rosalyn, kindergarten and grade 1 teacher)

\section{Work/home life balance}

In terms of the pandemic response, the participants' strongest reaction involved the historic shift that took place in the work/home balance. For the first time in all of our lives, many of us were working from home as part of the provincial health strategy to create household isolation and mitigate viral transmission. Essential service workers, including teachers working outside the home, had to develop various safety measures when re-entering their homes at the end of the day. These changes, both working from home and creating a safe place in the home, made viral transmission and space part of our new ways of thinking and living alongside the coronavirus. Most of the parents we interviewed were trying to work from home while attending to the needs of their own school-aged children. This required creating a quiet workspace and navigating work responsibilities, while still caring for the holistic needs of their families. In some cases, this also involved financial worry: many partners were sorting through an uncertain future for their family business or a reduction in work hours. For teachers who had children, this was characterized as a juggling act, where the teacher was wearing many hats and responsible for both their own and other children's needs. One parent also longed for her pre-Covid life and was deeply saddened by the situations in local care homes, recalling her mother's situation. 
I just want the kids lives and our lives to go back to normal. I haven't seen or touched my mother since March [upset] and I can, we can only see her from the porch, so I just...I'm craving my life back and I'm craving it for my kids. (Elise, parent of 4 children in elementary to high school)

I have a whole lot less patience, than I did before. Mm hmm. With my kids, they have honestly been driving me up the wall...I'm [working and commuting] a 10-hour day. Yeah. And then I'm getting home and I'm doing homework and, you know, and I'm fighting with kids because I'm not doing it right. Yeah. Or I'm not understanding it so I'm getting frustrated and having the kids stuck at home, we're now getting on each other's nerves a whole lot more. (Sara, single parent of 3, essential service worker)

I'm talking to other parents in the neighborhood everybody had a different set of stressors. Some whose employees were expecting them to be on call from 8:00 AM to 5:00 PM like they normally would be in the office but with two children at home and home schooling them and depending on their age having two parents with headsets on a computer or 8 hours a day it's just an unrealistic expectation so we didn't have that stressor, but we had the stress of "Oh my God What is this going to mean for the business that we've had for 13 years?" and we've put our entire life into building this business and then having it unravel, that placed a lot of stress on us.

I've moved my desk in the house about three times I think I finally found a spot where it's going to be the best kind of situation in terms of just finding a quiet space where I can actually shut the door so normally I'd have my laptop it wouldn't matter where my desk was because the kids would be gone all day. (Rochelle, parent of two children in elementary school)

I think probably the most challenging thing is wearing many hats at once and not being able to devote 100\% of your attention to one thing, so you know if you're working from home and trying to homeschool your own children. (Jan, primary teacher and Montessori resource consultant)

Both single mothers we interviewed spoke of going to work outside of the home as a "break" or as their "downtime", where they could escape the extreme pressures at home.

\section{Holistic teaching responses}

Many teachers were apprehensive about returning to school, and some did not feel safe to do so. It turned out to be better than some imagined it would be, but teachers are still concerned about the virus when schools open in the fall. All the elementary school teachers and one middle school teacher talked about how difficult it was to keep children apart when schools reopened in June, even with reduced numbers of children.

That was manageable, as far as keeping peers apart in the classroom because they needed their designated spot to sit. When they got out onto the playground, they would forget that and their heads come close together because they want to chat or share something or look at something close together. (Rosalyn, kindergarten and grade 1 teacher)

One thing that is not working super well is that kids are not social distancing. It's really hard to police that and kids are not always washing their hands if you tell them 
to and it's really hard to police that as well. (Karley, grade 7 and 8 French Immersion teacher)

Constantly monitoring children to reduce the spread of the virus was a new aspect of teachers' roles during emergency teaching when schools re-opened, and some found this responsibility exhausting. They wonder how maintaining physical distancing will be possible if schools are back full-time for all students in the Fall.

The physical distancing rules and preventative measures, such as wearing a mask, also presented a challenge for teachers when extending care to their students, particularly for young children.

You want to talk to the kids and be close. If they hurt themselves you [want to] give them the hug. And you, if you have to wear a mask, what's [that] like? Because [normally] you smile and your facial expression shows them how you care [so now] how does that all fit in. When you have all these rules and regulations. They want to come up and talk to you and you say, step back. How does that feel to a little one and how do you still make them feel loved and cared for? That's going to take extra effort. (Rosalyn, kindergarten and grade 1 teacher)

Teachers also assumed new heightened roles when assisting families in their schools who were struggling, often with mental health support and obtaining basic necessities such as food.

Yeah, I think the academics are important, but I think that we've got to look more holistically [at] the family. What else do they need for support? How do you offer that virtually? You know, that's tricky, right? (Mia, K-9 distributed learning teacher)

Some of these families were not vulnerable prior to the pandemic, so it became teachers, rather than councillors or other support staff, who were most aware of their current situation and who were best positioned to help them remotely. This was challenging, and teachers needed support to assume these more holistic ways of caring for children and families.

\section{Communication}

In general, there was confusion and lack of clarity for both parents and teachers regarding schooling expectations, decisions, practices, and protocols. Some teachers felt that information was not forthcoming from their employer or union and they had to personally monitor newspapers and broadcasts from the provincial government for information. There was also a concern about the spread of misinformation.

This is actually something I talked to my principal about. I often hear from the news first rather than from our principals, from our district. It's pretty sad when we have to carefully watch the news and stay tuned to find out what's happening with our own work. (Brenda, technology teacher and single parent of 2)

I didn't feel like our [teachers' association] wasn't sharing, very much information for quite some time. They weren't sharing as much as they could have with us, our local union. (Mia, K-9 distributed learning teacher)

One teacher reported reading in a local community newspaper that parents were going to be helping write report cards, which was certainly not that case at her school. She noted, "you have to read through the fake news. You got to be really careful". 
There was a general lack of clarity about what "continuity of learning" and emergency teaching should entail for educators and families. The return to in-class instruction in June was confusing for some parents, and they were hoping for more clarity from the government and more direction from the schools.

I didn't understand why schools were opening back up in June. Was it about care? Was it an experiment to see what would happen? Was it to enculturate children with the "new normal" of school so they would be prepared for the fall? Was it to have closure for the school year? Was it to support children's mental health? I didn't understand the reason and I didn't understand the risks, and I felt like I couldn't make an informed decision. (Kelly, parent of three)

One of the frustrations both teachers and parents reported arose when their emails went unanswered. Parents felt unsupported when they had to email multiple times to receive a response from their child's teacher, and teachers felt extremely concerned when students and parents did not reply to their emails, making it very difficult to know what was occurring and how to best support families.

\section{General recommendations}

We found that the participants, both parents and teachers, were highly tolerant and understanding of the need for the measures taken - and ultimately, they did their best to support student learning, despite multiple challenges. We were surprised by many of the adjustments that both groups made to be able to quickly meet educational needs to the best of their ability. Students were also characterized in many discussions as "tough" or "resilient", and both parents and teachers felt optimistic in the long run about the efforts that were made at the end of the school year. It was noted, however, that this experience was overwhelming and unsustainable for parents, and all the teachers reported the loss of community and responsiveness to social and educational cues that they normally received from their students through direct observation and incidental communication and conversations. When parents considered being their children's teachers again in the Fall, they felt unequipped to tutor and support their discipline-specific needs, especially across siblings, with vulnerable children, and while working.

In light of these findings, we recommend that:

- Information be communicated to parents and teachers as early as possible, to provide time to plan for probable changes to the regular class composition and schedule.

- Extra attention and support be given to vulnerable groups, including single-parent families, parents with at-risk children, or children who require additional educational services, tutoring, or EA support.

- Clear expectations around attendance and grading be communicated.

- Communication be centralized within schools and among schools, the District, the Ministry, and families, to ensure consistency.

- Work/home life balance be addressed through additional instructional support for families to ensure that families' childcare, tutoring care, and out of school care needs be met in timely and affordable ways during periods of remote learning.

- Alternative spaces, such as outdoor education, be used to minimize airborne transmission, reducing classroom density and the chance of spreading the virus. 
- Increased support and/or adapted schedules be provided for students entering grades $\mathrm{K} / 6 / 9$.

- Attention be paid to the delicate balance between attending to school/work and mitigating the spread of the virus by planning for illness and absences.

- One-on-one, regular face-to-face assistance be maintained for children with support needs, even during remote instruction.

- Prioritize social/emotional wellness in schools, and address holistic support through ready access to counselling and tutoring services for students, teachers, and families.

- Students, parents and teachers continue to exercise tolerance, knowing that everyone has experienced many disruptions to their routines, and with few exceptions have been living in very stressful situations.

\section{References}

Earn, D. J., He, D., Loeb, M. B., Fonseca, K., Lee, B. E., \& Dushoff, J. (2012). Effects of school closure on incidence of pandemic influenza in Alberta, Canada. Annals of Internal Medicine, 156(3), 173-181.

Effler, P. V., Carcione, D., Giele, C., Dowse, G. K., Goggin, L., \& Mak, D. B. (2010). Household responses to pandemic (H1N1) 2009-related school closures, Perth, Western Australia. Emerging Infectious Diseases, 16(2), 205-211.

Government of Canada (2020). Coronavirus disease (Covid-19): Outbreak update. https://www.canada.ca/ en/public-health/services/diseases/2019-novel-coronavirus-infection.html?topic=tilelink.

Horgan, J. (2020). Covid-19 BC education update, May 15. https://www.youtube.com/watch?v=96E1N AVD_iU\&feature $=$ youtu.be.

Johnson, A., Moore, Z. S., Edelson, P. J., Kinnae, L., Davies, M., Shay, D. K., et al. (2008). Household responses to school closure resulting from outbreak of Influenza B, North Carolina. Emerging Infectious Diseases, 14(7), 1024-1030.

Lee, B. Y., Brown, S. T., Cooley, P., Pottr, M. A., Wheaton, W., Voorhees, R. E., et al. (2010). Simulating school closure strategies to mitigate an influenza epidemic. Journal of Public Health Management \& Practice, 16(3), 252-261.

Ministry of Education (2020). Frequently asked questions (FAQs) on continuity of learning K-12 education system. Victoria, BC: Ministry of Education. https://www2.gov.bc.ca/assets/gov/education/administra tion/kindergarten-to-grade-12/safe-caring-orderly/bc-ministry-of-education-questions-and-answerscontinuity-of-learning-k-12-education_system.pdf.

Sadique, M. Z., Adams, E. J., \& Edmunds, W. J. (2008). Estimating the costs of school closure for mitigating an influenza pandemic. BMC Public Health, 8, 135-142.

Saldaña, J. (2016). The coding manual for qualitative researchers (3rd ed.). Los Angeles, CA: Sage.

Wu, J. T., Cowling, B. J., Lau, E. H. Y., Ip, D. K. M., Ho, L., Tsang, T., et al. (2010). School closure and mitigation of pandemic (H1N1) 2009, Hong Kong. Emerging Infectious Diseases, 16(3), 538-541.

Publisher's Note Springer Nature remains neutral with regard to jurisdictional claims in published maps and institutional affiliations.

Margaret MacDonald is an Associate Professor in the Faculty of Education at Simon Fraser University in Burnaby, British Columbia, Canada. Her research focuses on pedagogical documentation and responsive, generative curriculum practices in early childhood and teacher education.

Cher Hill is an Assistant Professor and an in-service and pre-service teacher educator in the Faculty of Education at Simon Fraser University. She supports teachers in studying their own practice as educators through the use of self-study and practitioner inquiry methodologies. Her current research utilizes new materialist theories to make visible the complex relations between human and more-than-human entities within educational contexts. She is a passionate supporter of participatory learning and community-based educative initiatives. Her recent work involves collaborating with community partners to educate citizens about the impact of colonization on the Fraser watershed and mobilizing them to restore local creeks. She has a background in gender and education and brings a critical feminist lens to her work. 